\title{
Artículos
}

\section{Las principales tensiones de una futura regulación de las técnicas de reproducción asistida en Chile: especial referencia a la filiación ${ }^{*}$}

Susana Espada Mallorquín ${ }^{* *}$

RESUMEN

El presente artículo plantea los dilemas básicos a los que el legislador chileno se enfrenta a la hora de regular las técnicas de reproducción asistida. Analiza los proyectos presentados hasta la fecha y las principales discrepancias doctrinales desde una perspectiva crítica. Se toma como marco de referencia el derecho comparado. De igual forma, como ejemplo de la incertidumbre que genera la falta de normativa, se analizan algunos de los principales problemas de la determinación de la filiación, derivada del uso de estas técnicas.

\section{ABSTRACT}

This article consider basics dilemmas that the Chilean legislator due to deal with for regulate the assisted reproductive technology, analyzing different projects presented to date and the principals academy disagreements from a critical perspective and considering the Comparative law. In the same manner and like an example of the uncertainty that the lack of regulation generate, the article study some of the principal problems relate to filiation determination derivate of the use of this technology.

PALABRAS CLAVE

Reproducción asistida, filiación, autonomía reproductiva. 


\section{KEYWORDS}

Assisted reproductive, filiation, reproductive autonomy.

SUMARIO

1. Introducción

2. Tensiones jurídicas en la regulación de las técnicas de reproducción asistida

3. Problemas para determinar la filiación derivada de la reproducción asistida

4. Conclusión

\section{INTRODUCCIÓN}

El contexto chileno del derecho comparado respecto a la fecundación mediante técnicas de reproducción humana asistida (en adelante TRA) es peculiar. ${ }^{1}$ Chile no cuenta con una ley especial sobre dichas técnicas, si bien existe alguna regulación de carácter administrativo para el sistema público de salud. ${ }^{2}$ En la práctica, esta falta de regulación ha sido suplida por la autorregulación de los centros clínicos y por sus términos contractuales. Aquellos centros que son miembros de la Red Latinoamericana de Reproducción Asistida se adhieren a un marco consensuado

* El presente artículo se enmarca en el desarrollo del proyecto CEAL-AL2015-02: "Presente y futuro de la reproducción asistida en el derecho de familia del siglo XXI en España y América Latina (especial referencia a Argentina, Chile y México). Aspectos jurídicos, sociales y éticos". La investigadora principal es Pilar Benavente Moreda; la autora es investigadora principal del grupo chileno.

** Doctora en Derecho por la Universidad Autónoma de Madrid. Profesora asociada de la Facultad de Derecho de la Universidad Adolfo Ibáñez. (susana.espada@uai.cl)

${ }^{1}$ Bascuñán señala que dentro del derecho europeo tenemos dos perspectivas contrapuestas, la del Informe Warnock (Reino Unido, 1984) y la del Informe Benda (República Federal Alemana, 1986). Ambos inspiran sendos modelos regulativos: el de protección del embrión diferida al día 14 -modelo inglés, seguido por la legislación española - y el de la protección temprana del cigoto -modelo alemán-. Ambos modelos han evolucionado a la luz del desarrollo científico y tecnológico, pero sus definiciones estructurales se han mantenido, tanto en lo que respecta a sus coincidencias como a sus divergencias. BASCUÑÁN RODRÍGUEZ, ANTONIO, "La fecundación in vitro ante el Derecho penal chileno", en Técnicas de reproducción humana asistida. Desafíos del siglo XXI: una mirada transdisciplinaria, Santiago, Universidad de Chile, 2013, pp. 261-262.

${ }^{2}$ Por ejemplo, la Ley 20.190 sobre experimentación con células madre, que prohíbe la clonación de humanos y que declara la protección del ser humano desde la concepción (artículo 1). 
por la comunidad médica internacional, la cual fija una especie de protocolo. ${ }^{3}$ No obstante, no hay una norma común. Por otro lado, se han presentado varios proyectos para regular la reproducción asistida, pero ninguno de ellos ha prosperado hasta la fecha.

Esta situación de incertidumbre no ha impedido que en Chile exista una amplia y sofisticada oferta de TRA. Si bien es mucho más baja si la comparamos con Europa, no deja de ser significativa. Así, entre 1990 y 2009, hubo más de 5500 nacimientos gracias a este tipo de técnicas. ${ }^{4}$ Eso sí, en su mayoría el sector privado de salud provee a pacientes de altos medios económicos. Este sector ha tenido un desarrollo sostenido gracias al clima de libertad económica imperante en Chile. ${ }^{5}$ Aunque la comunidad médica reconoce la incertidumbre jurídica en la que se desarrollan las TRA en Chile, la actitud que prevalece es la de preferir esta incertidumbre y mantener el status quo, a la posibilidad de que se regule la práctica legislativamente. Esto es así, porque se prevé que de regularse la práctica, ésta se restringiría en forma considerable y primarían criterios ideológicos por sobre los criterios técnicos y bioéticos, a los que ya se han acostumbrado quienes proveen estos servicios.

Actualmente, las disputas ideológicas en el Congreso chileno están concentradas en la despenalización parcial del aborto por tres causales (terapéutica, inviabilidad fetal y violación). Quienes se oponen a la despenalización y defienden la prohibición absoluta afirman que el derecho a la vida comienza desde el momento de la unión del óvulo con el espermio. De abrirse la discusión legislativa sobre las TRA, estas personas tendrían que defender el mismo principio.

\footnotetext{
${ }^{3}$ CAsas Becerra, Lidia, "Los desafíos para Chile de la decisión Artavia Murillo contra Costa Rica de la Corte IDH (caso fertilización in vitro): Algunos comentarios", en Anuario de derecho público, Santiago, Universidad Diego Portales, 2013, pp. 406-407.

${ }^{4}$ SOCMER, 20 años de reproducción asistida. Registro chileno de reproducción asistida 1990-2009. Disponible en: http://www.socmer.cl/registro-chileno-1990-2009.pdf

${ }^{5}$ ZEGERS-HOCHSCHILD, FERNANDO, NYGREN, KARL G. Y ISHIHARA, OSAMU, "The impact of legislation and socioeconomic factors in the access to a global practice of assisted reproduction", en Texbook of Assisted Reproductive Techniques: Clinical Perspective, Florida, 2008, pp. 442-444; ZEGERSHOCHSCHILD, FERNANDO, "Algunas reflexiones éticas en el uso de la tecnología reproductiva moderna para el tratamiento de la infertilidad", Revista Médica Clínica las Condes, vol. 21, No. 3, Santiago, 2010, pp. 475-476, y ZEGERS-HOCHSCHILD, FERNANDO, SCWARZE, JUAN ENRIQUE, CROSBY, JAVIER y BORGES, MARÍA DO CARMO, "Twenty years os Assisted Reproductive Technology ART) in Latin America”, en JBRA Assit. Reprod., vol.15, No. 2, March-April, 2011, pp. 19-30.
} 
En la práctica, esto los obliga a oponerse a muchos de los procedimientos que se consideran buenas prácticas médicas (por ejemplo, la posibilidad de criopreservación o selección de embriones por graves problemas genéticos). Esta postura es incómoda para quienes se identifican como "pro-vida", porque implica sostener una postura impopular. A diferencia de lo que sucede con el aborto, las TRA no están estigmatizadas en la sociedad chilena y existe un amplio apoyo de la práctica. ${ }^{6}$ Además, la negativa a la realización de estas técnicas reproductivas implicaría, en la práctica, prohibir la prestación de servicios médicos que actualmente entregan importantes actores privados, limitando la libertad de trabajo y la libertad económica.

Confrontada la realidad jurídica con la sociológica, es oportuno precisar cuáles son las principales tensiones que deberían enfrentarse en una futura regulación de las técnicas de reproducción asistida en Chile.

2. TENSIONES JURÍDICAS EN LA REGULACIÓN DE LAS TÉCNICAS DE REPRODUCCIÓN ASISTIDA

En este apartado seguiremos a Bascuñán, quien destaca que las tensiones jurídicas de la propuesta de regulación de las TRA se deben a que por su particularidad generan "un trilema práctico". Destaca que a la hora de plantearse

${ }^{6}$ Según la Encuesta de Opinión Pública sobre Reproducción Humana y Usos de Tecnología Reproductiva Moderna realizada por el Programa de Ética y Políticas Públicas en Reproducción Humana de la Universidad Diego Portales, $89 \%$ de los encuestados se manifiesta de acuerdo con la afirmación "toda persona tiene derecho a hacer uso de los avances de la medicina para concebir un hijo"; $72 \%$ de los encuestados apoya la fecundación in vitro: es la posición más fuerte entre las personas de grupos socioeconómicos medio alto y los menores de 44 años. Seis de cada diez encuestados consideraría el uso de la fecundación in vitro si después de un tiempo de intentarlo no lograra tener hijos, y sólo $21 \%$ de los consultados sostiene que no consideraría el uso de esta técnica. A pesar de que $81 \%$ de los encuestados se identifica con una religión y $61 \%$ señala que es católico, sólo $17 \%$ está de acuerdo con los enunciados "mi religión no es compatible con la fecundación in vitro" y "el uso de la fecundación in vitro no es correcto pues es jugar a ser Dios". Aunque $62 \%$ cree que existe una nueva persona desde el momento de la unión del óvulo con el espermio y $23 \%$ a los cinco días después de la fecundación (anidación del embrión), $74 \%$ de los encuestados está de acuerdo con el congelamiento de embriones si se utilizan para que una pareja intente futuros embarazos y $63 \%$ está de acuerdo en que una pareja done embriones para realizar una investigación que pueda contribuir a curar enfermedades. La encuesta se aplicó a personas cuyos rangos etarios fluctuaron entre los 18 y 65 años, residentes de las 34 comunas del Gran Santiago. Véase Herrera, Florencia, Teitelboim, Berta, Russo, Moisés, Salas, Sofía Y ZegersHOCHSCHILD, FERNANDO, "Encuesta de opinión pública sobre reproducción humana y usos de tecnología de reproductiva asistida en habitantes de Santiago, Chile", Revista Médica de Chile, No. 141, Santiago, 2013, pp. 853-860. 
una futura regulación de las TRA habría como mínimo tres bienes o intereses en conflicto: la autonomía reproductiva positiva de la mujer (o la pareja, según la decisión que la legislación eventualmente adopte), la autonomía reproductiva negativa de la mujer a quien se hará la transferencia de los embriones fecundados in vitro y la supervivencia de esos embriones. ${ }^{7}$

La Sala Constitucional de la Corte Suprema de Costa Rica decidió, en su sentencia de 15 de marzo de 2000, que la solución correcta ante este primer dilema, relativo a la autonomía reproductiva positiva, se encontraba en la prohibición de las TRA. Al igual que otros autores, considero que el razonamiento de la Corte Suprema costarricense resulta inconsistente, pues para evitar una eventual puesta en peligro de la supervivencia de embriones humanos se toma una decisión que disminuye drásticamente sus posibilidades de existencia. ${ }^{8}$ No obstante, esta decisión prohibitiva de las TRA es un caso aislado que, como señalaremos a continuación, ha sido condenado por la Comisión Interamericana de Derechos Humanos.

Ante esta primera tensión, en Chile, hasta la fecha sólo dos proyectos se han presentado para regular la TRA; ambos autorizaban la fecundación in vitro. ${ }^{9}$ Ninguno la menciona expresamente en su regulación, pero se deja constancia en su fundamentación que la entienden incluida en la expresión "técnicas de reproducción asistida" empleada por su articulado. Los opositores a la regulación adujeron ante la Comisión de Constitución, Legislación, Justicia y Reglamento, la "ilicitud radical" de la fertilización asistida en virtud de la "ruptura del acto conyugal unitivo y procreativo" que ella suponía, además del riesgo que la fecundación in

\footnotetext{
7 BASCUÑÁN ROdRíGUEZ, ANTONIO, "La fecundación in vitro ante el Derecho penal chileno", en Técnicas de reproducción humana asistida. Desafíos del siglo XXI: una mirada transdisciplinaria, Santiago, Universidad de Chile, 2013.

${ }^{8}$ Bascuñán señala que "la respuesta de que una incidencia negativa sobre la tasa de natalidad no es moralmente conmensurable con la asunción del riesgo de muerte de seres humanos vivos no es satisfactoria. Pues lo crucial para la aceptación de un margen de riesgo permitido es la razón que lo justifica. Y si algo puede justificar un riesgo de no sobrevivir es el incremento exponencial de la chance [sic] de ser engendrado", BASCUÑ́N RODRíGUEZ, ANTONIO, "La fecundación in vitro ante el derecho penal chileno", en Técnicas de reproducción humana asistida. Desafíos del siglo XXI: una mirada transdisciplinaria, Santiago, Universidad de Chile, 2013, p. 268.

9 Proyecto sobre principios jurídicos y éticos de las técnicas de reproducción humana asistida (Boletín 1026-07), presentado por el senador Piñera y el proyecto de ley sobre reproducción humana asistida (Boletín 4346-11) del senador Ruiz-Esquide.
} 
vitro implicaba para la supervivencia de embriones no transferidos. No obstante, en la comisión, el primer proyecto fue aprobado por unanimidad, entendiendo que la regulación legal de las técnicas de reproducción asistida representaba una valiosa oportunidad para proteger al embrión humano, bajo el imperativo del artículo 19 numeral 1 de la Constitución Política. En virtud de esta consideración, el aseguramiento legal del ejercicio de la autonomía reproductiva positiva se sustituyó por la protección del embrión fecundado in vitro como preocupación prioritaria de la política legislativa chilena en esta materia. ${ }^{10}$

Respecto de la autonomía reproductiva positiva, las discusiones parlamentarias permiten pensar que, en general, en Chile existe un contexto favorable a la autorización de las TRA, aunque lo cierto es que todos los proyectos han sido archivados hasta la fecha. Sin embargo, considero que se trata de una aceptación que no se basa en la protección del derecho a la autonomía reproductiva de la mujer o de los miembros de la pareja, sino en una idea más general de que las personas tienen derecho al libre acceso a prestaciones de salud (como afirma el artículo 19.9) y de libertad económica de los proveedores de salud (centros, clínicas, etcétera).

De adoptarse la decisión de autorizar las TRA, es esencial determinar en qué momento del proceso productivo se considera constituido al embrión. En este punto, la sentencia de la Corte Interamericana de Derechos Humanos (CIDH) en el caso Artavia Murillo tiene una trascendencia esencial en el sistema de derecho internacional de derechos humanos, porque es la primera vez que ese tribunal se pronuncia directamente sobre la aplicación, respecto de embriones, del artículo 4.1 de la Convención Americana de Derechos Humanos (CADH), que consagra el derecho a la vida "en general, desde el momento de la concepción".

En dicha sentencia, la CIDH declaró que la expresión concepción alude al momento de la implantación del óvulo fecundado en el útero y que, por lo tanto, el artículo 4 no es aplicable a los embriones antes de la implantación. Agregó que el

\footnotetext{
${ }^{10}$ Para un análisis de la tramitación y evolución de estos proyectos véase BASCUÑán RODRíGUEZ, ANTONIO, "La fecundación in vitro ante el derecho penal chileno", en Técnicas de reproducción humana asistida. Desafíos del siglo XXI: una mirada transdisciplinaria, Santiago, Universidad de Chile, 2013, pp. 277-286.
} 
embrión no es persona desde la perspectiva de la CADH y que la protección que le reconoce el artículo 4.1 a los no nacidos a partir de la implantación es de carácter gradual o incremental y no absoluto. De acuerdo con la Corte, la protección absoluta del derecho a la vida del embrión que pretende Costa Rica es contraria al objeto y fin de la Convención: la protección de todos los derechos humanos. El artículo 4.1, mediante la expresión y en general, tiene como fin permitir excepciones a la protección de la vida prenatal para no anular el goce y ejercicio de otros derechos reconocidos en la CADH. ${ }^{11}$

La Corte, en la mencionada sentencia, hizo una revisión de los textos y los trabajos preparatorios de declaraciones y tratados de derechos humanos tanto del Sistema Interamericano como del Sistema Universal: la Declaración Universal de Derechos Humanos, la Declaración Americana de Derechos Humanos, la Convención Americana de Derechos Humanos (CADH), el Pacto de Derechos Civiles y Políticos (PDCP), la Convención sobre los Derechos del Niño, y la Convención para la Eliminación de todas las Formas de Discriminación contra la Mujer. Concluyó que estas declaraciones y tratados no sustentan la afirmación de que el embrión pueda considerarse persona bajo el derecho internacional de los derechos humanos. Aunque hizo esta afirmación para argumentar que una interpretación sistemática del artículo 4 de la CADH que tomara en cuenta los otros tratados y declaraciones relevantes no sustentaban la tesis de la personalidad que había defendido la Corte Suprema de Costa Rica.

La interpretación que hizo la Corte de esos tratados ciertamente tiene otro efecto: establece un precedente significativo para la comprensión que los organismos internacionales, los Estados y los órganos de supervisión de los respectivos tratados pueden tener en el futuro de la situación del nasciturus bajo esos otros tratados. ${ }^{12}$ No obstante, como ha señalado parte de la doctrina, más allá de constituir un argumento poderoso en manos de quienes defienden el derecho al acceso a las técnicas de reproducción asistida, el efecto real que

\footnotetext{
${ }^{11}$ Sentencia de la Corte Interamericana de Derechos Humanos. Caso Artavia Murillo y otros (Fecundación in vitro vs. Costa Rica). Sentencia del 28 de noviembre de 2012.

12 ZUÑIGA, FRANCISCO, "Sentencia de la Corte Interamericana de Derechos Humanos en el caso Artavia Murillo y otros (fecundación in vitro) vs. Costa Rica", Anuario de Derecho público UDP, Santiago, 2013, pp. 347-373.
} 
puede tener el caso Artavia Murillo en el derecho chileno es, sin embargo, incierto. $^{13}$

Esto se debe a que en Chile aún existe una importante discrepancia en la doctrina constitucional sobre la jerarquía de las normas de los tratados internacionales de derechos humanos ratificados por Chile y, específicamente, sobre cómo se resuelven los conflictos si una norma de estos tratados es considerada contraria a una norma de la Constitución chilena. La Corte Interamericana entregó en el caso Artavia Murillo la interpretación oficial del artículo 4.1 de la CADH, que hasta antes de ese fallo era disputada. Por ejemplo, el Tribunal Constitucional chileno, en la sentencia sobre anticoncepción de emergencia, ${ }^{14}$ citó este artículo para afirmar que la Convención Interamericana de Derecho Humanos reconocía al nasciturus el derecho a la vida desde la fecundación. ${ }^{15}$ La nueva certeza sobre la interpretación oficial de la norma, sin embargo, no asegura que el legislador, el Tribunal Constitucional $u$ otros tribunales apliquen en Chile el artículo 4.1 así entendido.

Es posible que se considere que el artículo 4.1, bajo la nueva interpretación, contradice el texto constitucional chileno, si se entiende que este último reconoce el derecho a la vida desde la fecundación. Quienes suscriben esa tesis afirman además que los tratados internacionales tienen una jerarquía infraconstitucional en el derecho chileno, lo cual descartaría la aplicación del artículo 4.1 de la $\mathrm{CADH},{ }^{16}$ sin perjuicio de las responsabilidades internacionales en que puede incurrir el Estado de Chile.

Por su parte, desde la perspectiva constitucional, el artículo 19.2 de la Constitución chilena establece que "la ley protege la vida del que está por nacer".

13 RUIz Miguel, Alfonso y ZúÑIga FaJuRI, AlejandRA, "Derecho a la vida y constitución: consecuencias de la sentencia de la Corte Interamericana de Derechos humanos 'Artavia Murillo vs. Costa Rica', Estudios Constitucionales, año 12, No. 1, Talca, 2014, pp. 101-102.

${ }^{14}$ Sentencia del Tribunal Constitucional de 18 de abril de 2008, Rol 741-07 CDS, considerandos 49 y 53.

15 UnduRRAGA, VerónICA, "Anticoncepción de emergencia: autonomía de las adolescentes y derechos de sus padres", Anuario de Derechos Humanos, Santiago, 2007, pp. 163-171.

${ }^{16}$ Véase NogueIRA, HUMBerTo, "Consideraciones jurídicas sobre la jurisprudencia del Tribunal constitucional sobre tratados internacionales y derechos esenciales contenidos en tratados internacionales, después de la reforma constitucional de 2005”, Estudios constitucionales, vol. 11, No. 2, Santiago, 2011, pp. 97-154. 
En este punto, también existen importantes tensiones en la doctrina y jurisprudencia chilenas sobre el alcance que tendría la norma del inciso 2 de este artículo en materia de técnicas de reproducción asistida. El estatus jurídico constitucional del embrión pre-implantatorio, especialmente cuando se trata de embriones que se encuentran fuera del cuerpo de la mujer, tampoco está lógicamente zanjado en Chile.

En la citada sentencia del Tribunal Constitucional sobre anticoncepción de emergencia, se acogió — por cinco de nueve votos — la tesis de que el no nacido es titular del derecho a la vida desde el momento de la concepción. Por este momento se entiende el de la unión del óvulo con el espermio. Sin embargo, el ministro Venegas, que suscribió esta tesis, consideró que la Constitución sí admitía despenalizar el aborto bajo causales calificadas.

Entre los ministros de la minoría, hubo dos que no se pronunciaron sobre ese punto por considerarlo innecesario para resolver el caso (Correa Sutil y Fernández Fredes), un ministro que señaló que le corresponde al legislador precisar el instante y las condiciones en que debe comenzar a operar la protección constitucional de la vida prenatal (Colombo) y otro ministro que negó que el no nacido fuera titular del derecho a la vida (Vodanovic). Esta sentencia no se refiere específicamente (porque no distingue) entre los óvulos fecundados dentro o fuera del cuerpo de la mujer. ${ }^{17}$ Además, en el ordenamiento chileno, los fallos del Tribunal Constitucional no tienen valor de precedentes obligatorios. Por lo tanto, no puede considerarse que esta sentencia haya zanjado la discusión sobre el estatus jurídico del nasciturus. ${ }^{18}$

Por su parte, la Corte Suprema, el año 2001, declaró que el derecho a la vida comienza desde el momento de la concepción. ${ }^{19}$ Sin embargo, el año 2005

\footnotetext{
17 Marshall, Pablo, Zuñiga, Yanira, Accatino, Daniela y Bordalí, Andrés, "Sentencia sobre inconstitucionalidad del decreto supremo $n^{\circ} 48$ del Ministerio de Salud en la parte que autoriza la distribución de la 'píldora del día de después' en el Sistema público de Salud (Tribunal Constitucional)", Revista de Derecho, Universidad de Valdivia, julio 2008, pp. 155-170.

${ }_{18}$ Es interesante señalar, además, que el legislador, claramente desafiando lo resuelto por el Tribunal Constitucional, autorizó con posterioridad la repartición de la anticoncepción de emergencia en los servicios de salud pública en la Ley 20418, de 2 de febrero de 2010. Esta ley no fue impugnada ante el Tribunal Constitucional porque sus opositores no contaron el número de parlamentarios necesarios para hacerlo.

${ }^{19}$ Rol No. 2136-2001.
} 
señaló que el momento en que comienza la protección del que está por nacer "no está discernida científica y jurídicamente hablando", y que su sentencia del año 2001 carecía de cosa juzgada por ser de naturaleza cautelar. ${ }^{20}$ En consecuencia, ni la jurisprudencia del Tribunal Constitucional, ni la de la Corte Suprema puede llevar a concluir que la Constitución chilena prohíbe las técnicas de reproducción asistida, en razón del estatus constitucional del embrión.

De igual forma, desde una perspectiva constitucional, la regulación de dichas técnicas debe hacerse cargo de que el artículo 19 número 9 de la Constitución asegura a todas las personas "el derecho a la protección de la salud". Si bien hay consenso sobre el deber negativo del Estado de no obstaculizar el acceso a las TRA, es lógico pensar que de regularse esta materia, también se debería abrir una discusión sobre las obligaciones positivas del Estado de asegurar algún acceso real a personas por la vía de la provisión pública de estas técnicas y su financiamiento estatal ${ }^{21}$ y, por lo tanto, a su consideración dentro del derecho social a la salud. ${ }^{22}$

Desde el punto de vista científico, sólo se nos pueden clarificar características funcionales determinadas, pero no se puede afirmar si dichas características confieren al embrión la condición de ser humano. Como han señalado Ruiz y Zúñiga:

quien considera la vida humana del no nacido como un derecho absoluto debería cuestionarse su rechazo del valor gradual y progresivo de tal vida se debe no a la simple afirmación de que hay un código genético individualizado y con capacidad de autodesarrollo desde la fecundación,

\footnotetext{
${ }^{20}$ Rol No. $1039-2005$.

${ }^{21}$ Zegers-Hochschild, Fernando, Dickens, Bernard y Dughman, SANDRA, "El derecho humano a la fecundación in vitro", Revista Chilena de Obstetricia Ginecológica, vol. 79, No. 3, Santiago, 2014, pp. 233-234.

22 En la citada encuesta realizada por la Universidad Diego Portales en 2011, se indica que una abrumadora mayoría de los encuestados, 92\%, considera que el Estado debe participar en el financiamiento de las TRA. Eso sí, 48\% responde que este financiamiento debe focalizarse en las parejas que no pueden pagarla. Desde marzo de 2014, en Chile se financian ciertos tipos de TRA de baja complejidad. Véase HeRrera, Florencia, TeItelboim, BerTA, Russo, MoisÉs, Salas, Sofía y ZEGERS-HOCHSCHILD, FERNANDO, "Encuesta de opinión pública sobre reproducción humana y usos de tecnología de reproductiva asistida en habitantes de Santiago, Chile", Revista Médica de Chile, No. 141, Santiago, 2013, pp. 855-856.
} 
sino sobre todo a la suposición religiosa de que en ese momento el dios de su creencia infunde un alma inmortal a dicho ser. Si es así, resulta obligada la distinción que atraviesa el importante libro de Ronald Dworkin sobre el tema, Life's Dominion, entre criterios de virtud o bondad y criterios de corrección o justicia. Los primeros, entre los que se incluyen los preceptos y modelos religiosos, son ideales personales de vida buena que uno puede exigirse a sí mismo, pero que es injusto imponer coactivamente a los demás. ${ }^{23}$

Dicho lo anterior, y para seguir con este ejercicio que pone en evidencia las tensiones del proceso regulativo chileno, si en lugar de adoptar una opinión tradicional, aceptamos que la personalización es un proceso diferido en el tiempo y que la constitución del genoma humano en un embrión no es sinónimo de persona en potencia, ${ }^{24}$ tendríamos que analizar el siguiente dilema, al cual hemos denominado autonomía negativa.

La autonomía reproductiva negativa es otro importante interés en conflicto esencial a la hora de regular las técnicas de reproducción asistida. Esto es: si existe o no un deber de tolerar la transferencia del embrión fecundado in vitro o si aceptamos la revocabilidad del consentimiento inicialmente otorgado. Dentro del ámbito europeo, es indiscutible el principio de la revocabilidad esencial del consentimiento acerca de una intervención sobre el propio cuerpo. ${ }^{25}$ La primacía del derecho de la mujer a la inviolabilidad de su cuerpo, incluyendo su derecho a revocar el consentimiento previo a la transferencia del embrión, marca una diferencia sustantiva entre la protección del embrión in vitro, bajo la regulación legal de la fecundación in vitro, y la protección del embrión o feto anidado, bajo la

23 Ruiz Miguel, Alfonso y ZúñIga Fajuri, AlejandRa, "Derecho a la vida y constitución: consecuencias de la sentencia de la Corte Interamericana de Derechos humanos 'Artavia Murillo vs. Costa Rica', Estudios Constitucionales, año 12, No. 1, Talca, 2014, p. 98.

24 Zegers-Hochschild, FERnANDO, "Algunas reflexiones éticas en el uso de la tecnología reproductiva moderna para el tratamiento de la infertilidad", Revista Médica Clínica las Condes, vol. 21, No. 3, Santiago, 2010, pp. 472-474.

${ }^{25}$ Véase en este sentido, por ejemplo, en España, el artículo 2-4 de la Ley 35/1988 y su sucesor, el artículo 3-5 de la Ley 14/2006; o el artículo 161 del Código Penal de 1995 y, en Alemania, el § 4-12 ESchG, que sanciona con pena privativa de libertad de hasta 3 años y multa al que emprenda la transferencia de un embrión a una mujer sin su consentimiento. 
regulación de delito de aborto. Como señala Bascuñán: "El deber de tolerar el embarazo, afirmado por la prohibición penal de su interrupción, no implica un deber de tolerar el riesgo de embarazo. Por lo menos no cuando ese riesgo se produce en virtud de una intervención sobre el cuerpo de la mujer". ${ }^{26}$

La realización de la autonomía reproductiva positiva es congruente con el interés en la supervivencia del embrión; la realización de la autonomía reproductiva negativa, en cambio, pone en peligro su supervivencia. Si como se afirmó, al menos en la discusión de los proyectos legislativos lo esencial para el legislador chileno fue la protección del embrión, para evitar ese peligro sólo existen dos vías: prohibir la reproducción asistida o establecer para la mujer un deber de tolerancia de la transferencia del embrión fecundado in vitro (lo cual existe en algunas regulaciones latinoamericanas ${ }^{27}$ ). La primera vía afecta la autonomía reproductiva positiva de la mujer; la segunda lesiona su autonomía reproductiva negativa. ${ }^{28}$

Considero que la transferencia del embrión concebido in vitro a la mujer exige una intervención sobre su cuerpo, y toda intervención sobre el cuerpo de una persona competente requiere su consentimiento informado. Ese consentimiento es esencialmente revocable. La mujer en cuyo interés se efectuó la fecundación in vitro puede válidamente revocar su consentimiento en la transferencia del embrión. Sin embargo, la falta de norma explícita sobre autonomía negativa de la mujer implica un riesgo real de que, en el contexto de la

\footnotetext{
${ }^{26}$ BASCUÑÁN RodríGUEZ, ANTONIO, "La fecundación in vitro ante el derecho penal chileno", en Técnicas de reproducción humana asistida. Desafíos del siglo XXI: una mirada transdisciplinaria, Santiago, Universidad de Chile, 2013, p. 270.

${ }^{27}$ Artículo 488 del Código Civil de Coahuila en México.

${ }^{28}$ Por lo que se refiere a los proyectos, en ninguno de ellos la autonomía reproductiva negativa de la mujer que solicita la fecundación in vitro constituye un interés de peso equivalente a la protección de la vida o la dignidad del embrión. Ninguno de los proyectos distingue la posición de la mujer de la posición del hombre interesado en la reproducción asistida, ni consideran la posibilidad de la revocación del consentimiento. En las reformas de la Comisión de Constitución y de Salud sí se aceptaba la revocación del consentimiento por cualquiera de los miembros de la pareja, pero ninguno de los proyectos sanciona o prohíbe la transferencia de embriones sin el consentimiento de la mujer. En cambio, todos los proyectos establecen una pena privativa de libertad para la destrucción de embriones humanos o la acción de destruirlos, así como para su utilización o manipulación con fines distintos de la reproducción o terapia en interés del propio embrión.
} 
judicialización de un caso en Chile, al menos se intente exigir a la mujer que acepte la implantación de un embrión contra su voluntad.

Este derecho de autonomía negativa ha sido completamente invisible en Chile, en todas las discusiones parlamentarias de los proyectos de ley que se han presentado en el Congreso sobre reproducción asistida. Sin embargo, la preocupación por la preservación y el respeto a la dignidad del embrión es una consideración explícita y recurrente. Como ha señalado parte de la doctrina, la experiencia chilena y comparada sobre la regulación del aborto, de las cesáreas y cirugías intrauterinas contra la voluntad de la mujer embarazada, da pie para pensar en que es posible que, en materia de reproducción asistida también prime un régimen excepcional en el cual la indemnidad corporal de la mujer en el contexto de la reproducción reciba una protección disminuida. ${ }^{29}$

No obstante, la resolución del conflicto entre obligar a implantar y dejar morir el embrión puede posponerse mediante su criopreservación, esto es, su conservación por congelamiento por un tiempo potencialmente indefinido. De admitirse la regulación de la fecundación in vitro, considerando que el embrión preimplantacional no es persona y admitiendo la revocabilidad del consentimiento de la mujer, el último objeto de discusión es cómo regular la supervivencia de los embriones.

Desde el punto de vista de la futura regulación de las técnicas de reproducción asistida, la última tensión por resolver es si se prohíbe o se permite la criopreservación de embriones y el diagnóstico genético preimplatacional (DGP). El propósito médico de la criopreservación es compensar el margen de ineficiencia de la fecundación in vitro, y posibilitar una intervención mínima al cuerpo de la mujer para obtener los folículos y la fecundación de un número de embriones superior al que se transferirá en la primera intervención (embriones supernumerarios), para controlar su cantidad y calidad en cada transferencia

\footnotetext{
${ }^{29}$ BASCUÑÁN RODRíGUEZ, ANTONIO, "La fecundación in vitro ante el derecho penal chileno", en Técnicas de reproducción humana asistida. Desafíos del siglo XXI: una mirada transdisciplinaria, Santiago, Universidad de Chile, 2013, pp. 281-283.
} 
sucesiva. Por ello la criopreservación es el procedimiento alternativo a la obligación de transferir (o dejar morir) todos los embriones fecundados in vitro. ${ }^{30}$

La introducción de la técnica de la criopreservación plantea una nueva cuestión práctica: la compatibilidad entre el trato dado al embrión -su criopreservación potencialmente indefinida - y el respeto por la dignidad humana. Se debe tener presente el artículo 1 de la CPE, el cual establece que "las personas nacen libres e iguales en dignidad y derechos". En primer lugar, ante la necesidad de usar criterios de selección de embriones, podemos emplear la selección al azar o admitir el uso del diagnóstico genético preimplantacional (DGP) como un procedimiento que contribuye al refinamiento y precisión de los criterios de selección embrionaria. Bascuñán señala:

esto implica naturalmente un aumento del riesgo de omisión de transferencia de embriones, ya que mientras más información acerca de los embriones se disponga para su selección, bajo el principio del consentimiento informado, mayores son las razones que pueden existir para negarse a la transferencia. Por esa razón, la prohibición del DGP para favorecer la aceptación a ciegas de la transferencia de todos los embriones fecundados in vitro en un mismo procedimiento es una decisión legislativa restrictiva de la autonomía reproductiva negativa de la mujer. ${ }^{31}$

En este sentido, ninguno de los proyectos contempla reglas relativas al DGP, ni autorizándolo ni prohibiéndolo. Su regulación tampoco fue objeto de discusión, ni en la fundamentación de ambas mociones ni en el debate de las comisiones del Senado. ${ }^{32}$

\footnotetext{
30 BASCUÑÁn RODRÍGUEZ, ANTONIO, "La fecundación in vitro ante el derecho penal chileno", en Técnicas de reproducción humana asistida. Desafíos del siglo XXI: una mirada transdisciplinaria, Santiago, Universidad de Chile, 2013, p. 271; BECA, JUAN PABLO, LECAROS, ALBERTO, GonZÁLEZ, Patricio, Sanhueza, Pablo y Mandakovic, BorislalaVa, "Aspectos médicos, éticos y legales de la criopreservación de embriones humanos", Revista Médica de Chile, Santiago, 2014, pp. 903-904.

${ }^{31}$ BASCUÑ́N RODRÍGUEZ, ANTONIO, "La fecundación in vitro ante el derecho penal chileno", en Técnicas de reproducción humana asistida. Desafíos del siglo XXI: una mirada transdisciplinaria, Santiago, Universidad de Chile, 2013, p. 272.

32 Sólo Proyecto de Ruiz-Esquide pareciera ser pertinente al caso, al prohibir bajo pena la acción de manipular un embrión humano "con la finalidad de discriminar por razones no médicas" (artículo 11-5). La conjetura, contrario sensu de que se autoriza la selección de embriones atendiendo al
} 
En segundo lugar, tenemos que determinar el tratamiento definitivo de los denominados embriones supernumerarios. El respeto por la dignidad humana prohíbe discriminar entre las personas e instrumentalizarlas. De nuevo, concuerdo con Bascuñan en que "cuando no es la pertenencia a una determinada especie de seres vivos, sino la posesión de la calidad de persona lo que fundamenta la dignidad, entonces puede discutirse si el embrión humano posee o no esa calidad y consecuentemente esa dignidad". ${ }^{33}$ La opinión médica chilena mayoritaria acepta la criopreservación; eso sí, con una tendencia a reducir el número de embriones. ${ }^{34}$

Sin embargo, en todos los proyectos presentados para regular esta materia se prohíbe la criopreservación de embriones. Ni siquiera se autoriza en casos excepcionales de imposibilidad de transferencia. Ninguno de los proyectos regula la transferencia de embriones. En particular, ninguno ordena la transferencia de todos los embriones fecundados in vitro. No obstante, del hecho de que todos los proyectos prohíban bajo sanción penal la destrucción de embriones podría inferirse un deber de transferir todos los embriones fecundados, al menos contando con el consentimiento de la mujer. No obstante, ningún proyecto limita el número máximo de embriones por transferir en cada ciclo. ${ }^{35}$ Eso sí, todos los

diagnóstico de graves enfermedades hereditarias o patologías incompatibles con la viabilidad del embrión, es plausible atendiendo al tenor literal de la disposición, pero resulta incongruente con el contexto del proyecto. En él se prohíbe tanto la destrucción y crioperservación de embriones (artículo 11- 2). Eso sí, tratándose de la práctica del DGP, entre su autorización irrestricta para la selección de los embriones que posean cualquier clase de propiedad genética deseada y su prohibición absoluta existe la vía intermedia, consistente en autorizar su uso para la identificación de ciertas propiedades específicas; pero no sería admisible el uso de dicho diagnóstico, por ejemplo, para la selección del sexo.

33 BASCUÑÁN RODRÍGUEZ, ANTONIO, "La fecundación in vitro ante el derecho penal chileno", en Técnicas de reproducción humana asistida. Desafíos del siglo XXI: una mirada transdisciplinaria, Santiago, Universidad de Chile, 2013, p. 272.

34 Beca, Juan Pablo, lecaros, Alberto, González, Patricio, Sanhueza, Pablo y Mandakovic, BORISLALAVA, "Aspectos médicos, éticos y legales de la criopreservación de embriones humanos", Revista Médica de Chile, Santiago, 2014, pp. 906-907; ZEGERS-HOCHSCHILD, FERNANDO, "Algunas reflexiones éticas en el uso de la tecnología reproductiva moderna para el tratamiento de la infertilidad", Revista Médica Clínica las Condes, vol. 21, No. 3, Santiago, 2010, pp. 476-478.

${ }^{35}$ En lo que respecta a previsiones transitorias, en el proyecto de Ruiz-Esquide se establecía que para aquellos embriones criopreservados, al momento en que la ley habría de entrar en vigencia, quedarían sujetos a un plazo de cinco años para transferírsele a la mujer que solicitara su fecundación in vitro, a partir del cual pueden ser libremente adoptados por otras parejas (artículo 9a/b). Mientras ello no sucediera, se les debería mantener indefinidamente bajo criopreservación: se prohibió su destrucción (artículo 9-c). 
proyectos prohíben bajo pena privativa de libertad la utilización de embriones humanos para fines distintos de la reproducción. Declaran, asimismo, prohibida la fecundación con fines no reproductivos, aunque ninguno establece una sanción especial para la infracción de esa prohibición.

\section{PROBLEMAS PARA DETERMINAR LA FILIACIÓN DERIVADA DE LA REPRODUCCIÓN ASISTIDA}

Una vez apuntadas las principales tensiones legislativas sobre la reproducción asistida en Chile, es evidente que en la actualidad existen multitud de cuestionamientos. Así, hay un conjunto de problemas prácticos relevantes de carácter institucional y procedimental, como la determinación de las condiciones de la organización y el control de las TRA, la veracidad del flujo de información o la decisión sobre la confidencialidad de la información personal. Otro conjunto se refiere a problemas más bioéticos relativos a los posibles modos de generación de embriones in vitro y tratos del embrión, como la clonación, la desdiferenciación celular, la formación de híbridos o la intervención genética.

Finalmente, hay un conjunto adicional importante de problemas que se relaciona con aspectos de derecho sustantivo en el ámbito civil y penal. Dentro del ámbito civil, quizás las más relevantes son las definiciones legales de las relaciones de filiación respecto del embrión fecundado in vitro como su determinación cuando se usan gametos de terceras personas; el derecho al anonimato del donante, la posibilidad del uso de estas técnicas para mujeres solas; la transferencia del embrión a mujer distinta de la que pretende la maternidad o el uso de gametos de personas fallecidas.

El Código Civil chileno cuenta con una única regla. El artículo 182 establece "Que el padre y la madre del hijo concebido mediante la aplicación de técnicas de reproducción humana asistida son el hombre y la mujer que se sometieron a ellas. No podrán impugnarse la filiación determinada de acuerdo a la regla precedente, ni reclamarse una distinta". Por lo tanto, podemos afirmar que, en la disyuntiva del 
legislador a la hora de regular la filiación entre la voluntad y la biología ${ }^{36}$ cabría defender que es la voluntad de quien desea ser progenitor, con independencia del origen genético del material reproductor empleado, la que prima en Chile. La voluntad de generar un nuevo ser humano sustituye al dato biológico, convirtiendo en padre o madre a quien presta su consentimiento para someterse a las técnicas de reproducción asistida. Sin embargo, esta afirmación tiene múltiples matices. Su resolución es una incógnita para el ordenamiento chileno. Parte de la doctrina ya ha puesto en evidencia la necesidad de que los intereses del hijo se consideren en la regulación de la reproducción asistida. Critican la citada regla porque deja a un lado al hijo, siendo, como es, uno de los sujetos dignos de protección. ${ }^{37}$

De igual forma, respecto a la determinación de la maternidad, a la hora de determinar la maternidad, en la regulación chilena, no prevalece en realidad la voluntad de la mujer que decide someterse a estas técnicas, sino la verdad biológica. Madre es sólo la que gesta en su vientre, con independencia de quien sea la madre genética o quien diera su consentimiento para someterse a la reproducción asistida en un caso de gestación por sustitución (véase el artículo 183 del Código Civil).

Respecto de la determinación de la paternidad, lo más significativo en el caso de Chile es que no existe un control administrativo o judicial previo, como sí existe en la adopción, a la hora de determinar la forma de llevar a cabo la prestación de dicho consentimiento. ${ }^{38}$ Para determinar la paternidad, hay que precisar si hay o no matrimonio. Si la pareja que se somete a la reproducción asistida está casada y la procreación asistida es homóloga (con gametos de la pareja) y con el consentimiento del marido, el hijo será matrimonial y, en principio, en la práctica, el consentimiento se prestará en un formulario de la correspondiente clínica para llevar dicha fertilización a cabo.

\footnotetext{
${ }^{36}$ BARBER, Roncesvalles, "Reproducción asistida y determinación de la filiación", REDUR, No. 8, Madrid, 2010, pp. 26-28; MICHEL, GRIMALDI, "Observaciones sobre la verdad, la filiación y la reproducción médica asistida", Familia y discapacidad, Madrid, 2010, pp. 165-171.

37 TURNER, SusAn, Molina, MARCIA y MOMBERG, RODRIGO, "Técnicas de reproducción humana asistida. Una perspectiva desde los intereses del hijo", Revista de Derecho, Talca, 2000, pp. 13-26.

38 JARUFE, DANIELA, "Las filiaciones no biológicas derivadas de la aplicación de las TRHA", en Técnicas de reproducción humana asistida. Desafíos del siglo XXI: una mirada transdisciplinaria, Santiago, Universidad de Chile, 2013, pp. 83-90.
} 
Sin embargo, dado que dicho consentimiento no está regulado, podría suceder una procreación asistida homóloga sin el consentimiento del marido. Ante la ausencia de regla expresa en materia de consentimiento, se discute si debe primar la relevancia del consentimiento en estas técnicas y, por lo tanto, podría impugnarse en estos casos la paternidad; o si debe regir el principio de verdad biológica. Por lo tanto, no prosperaría una impugnación en cuanto que genéticamente el marido es el padre. ${ }^{39}$ En el caso chileno, a mi juicio, debería considerarse al marido como padre, porque si bien no hay norma expresa sobre el consentimiento, puede probarse que existió una aportación voluntaria de material genético, por alguien que no es un donante anónimo y, en virtud del principio del favor filii, se le atribuiría esa paternidad. Eso no impide plantearse que el marido pudiera exigir responsabilidad por los daños y perjuicios patrimoniales y morales, que el nacimiento del hijo no deseado reporta tanto a la madre como al centro médico, en caso de exigirse legalmente el consentimiento.

También puede realizarse una reproducción asistida heteróloga (donación de gametos masculinos) con consentimiento del marido. En estos casos, de estar casados la filiación sería matrimonial y se prohíbe la impugnación, salvo vicios del consentimiento o que la reproducción se produjese por causas distintas a la reproducción asistida, por ejemplo, como resultado de una infidelidad. Igualmente puede darse la procreación heteróloga sin el consentimiento del marido. ${ }^{40}$ En esos casos, la filiación sería matrimonial, pero el marido podría impugnarla probando que no aportó ni el elemento volitivo ni el biológico. De probarse las mencionadas circunstancias, en el ordenamiento chileno debiera prosperar la impugnación y no debería determinarse la paternidad, salvo un reconocimiento de complacencia.

En el caso de las parejas no casadas, tanto las firmantes de un acuerdo de unión civil como las parejas de hecho, tenemos que ver de nuevo todas las anteriores variables. Sin embargo, debemos tomar en cuenta que para los convivientes civiles heterosexuales (firmantes de un acuerdo de unión civil) entran

\footnotetext{
${ }^{39}$ FARNÓS, ESTHER, "La filiación derivada de la reproducción asistida: voluntad y biología", Anuario de derecho civil, vol. 68, fascículo 1, Madrid, 2015, pp. 52-55.

40 JARUFE, DANIELA, "Las filiaciones no biológicas derivadas de la aplicación de las TRHA", en Técnicas de reproducción humana asistida. Desafíos del siglo XXI: una mirada transdisciplinaria, Santiago, Universidad de Chile, 2013, pp. 87-90.
} 
en juego las presunciones de paternidad matrimoniales prevista en el Código Civil chileno, ${ }^{41}$ pero no para los convivientes civiles del mismo sexo, ni para las parejas de hecho (homosexuales y heterosexuales). Luego, si la procreación asistida homóloga es con consentimiento del varón de la pareja de hecho o del conviviente civil, la filiación quedaría determinada por el consentimiento al sometimiento a la técnica y sería no matrimonial (artículo 182). Si la procreación asistida homóloga es sin consentimiento del varón, de nuevo podría determinarse la paternidad o por vía de la presunción o acudiendo a las pruebas biológicas, porque podría probarse que hubo una aportación genética voluntaria inicial de la pareja y no de un donante anónimo, a efectos de determinar la filiación.

Por su parte, en la procreación asistida heteróloga con consentimiento del varón, la paternidad será del varón que consiente y no será posible su impugnación. Finalmente, si es heteróloga sin consentimiento del varón, su paternidad, en el caso de las parejas de hecho, sólo podrá determinarse por adopción o por complacencia, pues no habría ni elemento volitivo ni biológico. ${ }^{42}$ Sin embargo, con la introducción de la presunción de paternidad, en el caso de los convivientes civiles heterosexuales (artículo 21 de la Ley de Acuerdo de Unión Civil), dicha paternidad le correspondería al conviviente varón, si bien (al igual que se afirmó para el matrimonio) podría impugnar la filiación; debe probar que no aportó ni elemento volitivo ni biológico. En esos casos, de nuevo entiendo que debería prosperar la impugnación y no se determinaría la paternidad, salvo un reconocimiento de complacencia. En los casos de reproducción asistida solicitada por la mujer sola, la determinación de la paternidad sólo puede ser por reconocimiento de complacencia.

También se ha criticado el artículo 182 del Código Civil porque se considera que al impedir al menor la impugnación de la filiación determinada por reproducción asistida, priva de cualquier tipo de investigación sobre el

\footnotetext{
${ }^{41}$ En el artículo 21 de la Ley 20830 de Acuerdo de unión civil, que entró en vigor el 22 de octubre de 2015, se establece: "Para los efectos de la presunción de paternidad, en caso de convivientes civiles de distinto sexo se estará a las normas que la regulan en el artículo 184 del Código Civil".

42 JARUFE, DANIELA, "Las filiaciones no biológicas derivadas de la aplicación de las TRHA", en Técnicas de reproducción humana asistida. Desafíos del siglo XXI: una mirada transdisciplinaria, Santiago, Universidad de Chile, 2013, pp. 93-94.
} 
conocimiento de su padre biológico. En principio, cabría afirmar que en Chile en la actualidad rige el principio de anonimato del donante, lo cual garantiza la confidencialidad sobre su identidad. ${ }^{43}$

Dentro de la doctrina, algunos autores afirman la inconstitucionalidad del citado precepto. $^{44}$ Discrepo en ello, pues considero que si la base de la determinación de la filiación por reproducción asistida es la voluntad y no la bilogía o la genética, la regla del artículo 182 del Código Civil es coherente. Eso no significa que, a mi juicio, la defensa del anonimato del donante resulte difícilmente compatible con el derecho de los menores a conocer los orígenes, en cuanto a proteger el derecho a la dignidad y al libre desarrollo de la personalidad del nacido.

El anonimato concebido como secreto absoluto y no como una protección a la intimidad de las personas, implica cercenar el interés del hijo por conocer sus orígenes biológicos. Esa inmunidad jurídico-familiar del donante de semen o de óvulos carece de razón si tomamos en cuenta los intereses en conflicto: iría en contra de la Convención de los Derechos del Niño de la ONU. ${ }^{45}$ En estos casos, la identificación del progenitor biológico (no sólo con sus datos biogenéticos) no debe convertirlo en el padre legal. Debe permanecer como una mera declaración.

De igual forma, la doctrina chilena ha discutido sobre el acceso de las mujeres solas (solteras, divorciadas o viudas) a las técnicas de reproducción asistida. Como en el resto de ordenamientos, la piedra de toque de la discusión es

${ }^{43}$ En el ámbito del derecho comparado podemos destacar países como Francia, Dinamarca, España o Portugal, donde rige el principio de anonimato del donante, garantizando la confidencialidad sobre la identidad. Sin embargo, en Alemania, Suecia, Holanda, Austria, Reino Unido, Noruega, Finlandia, Nueva Zelanda, Victoria, Australia Occidental o Suiza, los hijos pueden conocer la identidad del donante cuando alcanzan la mayoría de edad o madurez suficiente. Según la doctrina del Tribunal constitucional alemán, el conocimiento del propio origen forma parte del derecho al libre desarrollo de la personalidad. En consecuencia, la promesa de anonimato hecha por el médico al donante y a la madre es nula, en tanto que se trata de un contrato en perjuicio de terceros. Otra modalidad es la vigente en la mayoría de los estados de Estados Unidos, donde el donante puede elegir si opta por el anonimato o por la posibilidad de ser identificado. Del mismo modo, los usuarios pueden optar por usa gametos de uno $u$ otro tipo de donantes.

${ }^{44}$ ROSENDE, HuGO, "¿Es inconstitucionalidad la norma del inciso $2^{\circ}$ del artículo 182 del Código civil chileno que impide impugnar la filiación determinada del hijo concebido mediante técnicas de reproducción humana asistida o reclamar otra distinta?, Revista Actualidad Jurídica, No. 23, enero 2011 , pp. 161-192.

${ }^{45}$ BARBER, RONCESVALLES, "Reproducción asistida y determinación de la filiación", REDUR, No. 8 , Madrid, 2010, pp. 34-35. 
si la reproducción asistida exclusivamente es un remedio a la infertilidad como una enfermedad diagnosticada o es la vía para reconocer un derecho a la mujer a la reproducción, un derecho a dar vida y, igualmente, si es legítimo ampara la creación de familias monoparentales.

$\mathrm{Si}$ toda persona es titular de un derecho reproductivo, entonces el ordenamiento jurídico debe reconocérselo y abrirle todas las posibilidades para su libre ejercicio y amparo. Por consiguiente, las técnicas de reproducción asistida deberían estar a disposición de cualquiera que las solicite, sea una mujer sola o con pareja, hetero u homosexual. De lo contrario, estaríamos conculcando su derecho en franca oposición a lo que le ocurre a la mujer con pareja heterosexual. Si la reproducción asistida tiene como fundamento de su acceso el "derecho a procrear" como emanación de la garantía constitucional del derecho a la vida (artículo 19, número 1), habría que reconocer el derecho de las mujeres solas a someterse a ellas. ${ }^{46}$

Tradicionalmente la doctrina ha presentado una dicotomía entre derecho reproductivo y derecho a la salud como justificación para la aplicación de las técnicas de reproducción asistida. La tesis del derecho a la protección de la salud como justificación para el acceso a éstas presupone considerar a la esterilidad como una enfermedad y a dichas técnicas como tratamiento terapéutico. Concordante con lo anterior, los destinatarios de la reproducción asistida son las parejas, e indirectamente, parejas heterosexuales. Por consiguiente, se excluyen como usuarios tanto a la mujer sola como a la pareja fértil, pues en ellos no existe incapacidad procreativa alguna que sanar. Estas técnicas sólo serán aplicables cuando los interesados, que deben ser parejas unidas por vínculo matrimonial o

\footnotetext{
${ }^{46}$ Desde una perspectiva de derecho europeo comparado, tenemos todas las posibilidades. En Suecia, Noruega, Italia o Francia se rechaza la posibilidad de que la mujer sola pueda tener acceso a estas técnicas. Mientras que en España, Gran Bretaña o Alemania, en principio, no hay problema en admitir el acceso de mujeres solteras a estos tratamientos. En estos países se afirma que si bien en un inicio las TRA estaban destinadas al tratamiento de la esterilidad de la pareja, casada o no, con un fin terapéutico, el derecho a la procreación de toda persona es una expresión de la libertad personal. De hecho en España, en la Exposición de motivos de la ley se afirma el derecho de la mujer a fundar su propia familia, eliminando cualquier límite que socave la libertad de procrear. Se afirma que pueden emplear esta técnica mujeres solas sin problemas infertilidad. TURNER, SUSAN, Molina, MARCIA y MOMBERG, RODRIGo, "Técnicas de reproducción humana asistida. Una perspectiva desde los intereses del hijo", Revista de Derecho, Talca, 2000, pp. 20-23.
} 
parejas estables, tengan dificultades para procrear y hayan sido médicamente descartadas otras terapias por ineficaces. ${ }^{47}$

Sin embargo, una actividad terapéutica consiste en un medio que tiende a reparar el funcionamiento de un órgano, con una intervención reparativa o sustitutiva, y para el beneficio del individuo sobre el que se interviene. Las técnicas de reproducción asistida no participan de estas características, puesto que no remedian la infertilidad, aun cuando permitan el nacimiento del hijo y además porque no necesariamente la intervención se realiza en el individuo que sufre la "enfermedad". ${ }^{48}$ Por otra parte, sería enfermedad la infertilidad sólo en aquellas parejas que quisieran tener hijos, lo que implicaría escudriñar la voluntad de los involucrados para determinar si la padecen o no.

Al igual que otros autores, entiendo que el derecho a la protección de la salud no puede constituir el único fundamento para el acceso a la reproducción asistida. Por el contrario, si tomamos como fundamento de su aplicación un derecho reproductivo autónomo e individual, me parece más cuestionable que no constituya una discriminación arbitraria la prohibición de acceder a ellas, recaída sobre la mujer sola y la pareja fértil. ${ }^{49}$ Eso sí, se suele argumentar al respecto que la razón suficiente para exigirle a la mujer que tenga una pareja es que en ese supuesto existiría un hombre dispuesto a consentir en su fertilización y a asumir la paternidad del que nazca, lo que incidiría directamente en el interés superior del niño y a su derecho a nacer y crecer dentro de una familia. ${ }^{50}$

Llama la atención la diferencia entre hombre y mujer en este punto. El varón también tiene derecho al libre desarrollo de su personalidad y a la paternidad, y también puede proporcionar a un hijo todas las condiciones para su perfecto desarrollo. Sin embargo, en Chile, no se contempla la procreación por maternidad subrogada, por lo que la única forma de ser padre solo, es la adopción.

${ }^{47}$ CORRAL, HeRnán, Familia y derecho: estudios sobre la realidad jurídica de la familia, Chile, Universidad de los Andes, 1994, pp. 155 y ss.

48 Zegers-HOChSCHILD, FERnANDO, "Algunas reflexiones éticas en el uso de la tecnología reproductiva moderna para el tratamiento de la infertilidad", Revista Médica Clínica las Condes, vol. 21, No. 3, Santiago, 2010, pp. 475-476.

49 TURNER, SUSAN, "Los derechos sexuales y reproductivos y su incidencia en la esterilización y procreación asistida", Revista de Derecho, Valdivia, diciembre 2001, pp. 214-216.

50 TuRner, Susan, Molina, MARcia y MOMBERG, RodRigo, "Técnicas de reproducción humana asistida. Una perspectiva desde los intereses del hijo", Revista de Derecho, Talca, 2000, pp. 20-23. 
A pesar de que con la reproducción asistida es posible separar gestación y genética, la mayoría de la doctrina chilena niega la admisibilidad de la maternidad subrogada. Los principales argumentos en contra son los siguientes: a) que esta técnica supone una explotación y manipulación de la mujer, sobre todo de escasos recursos económicos; b) que no se puede predecir de antemano el posible sufrimiento emocional de la madre gestante al desvincularse del nacido; c) que el equilibrio del niño puede ser influenciado por el comportamiento adoptado respecto a él durante el embarazo, por lo que, en la práctica, algunos ginecólogos no aceptan su realización si hay una contraprestación económica que puede generar un turismo procreativo, pero sí cuando esa gestación se hace en ayuda de un ser querido (caso italiano de madre e hija); y d) que se ignora la proporcionalidad del acto terapéutico, ya que se interviene a un sujeto sano. ${ }^{51}$

No obstante, es evidente que parejas chilenas pueden acudir al extranjero a países donde dicha maternidad se admite y pretender el reconocimiento filiativo del menor. ${ }^{52}$ En esos casos, hay que distinguir si lo que se pretende es directamente inscribir en el Registro civil chileno o la aprobación de la resolución judicial de un tribunal extranjero que determina la filiación. En el primer caso, según artículo 3.3 de la Ley de Registro Civil, debería inscribirse en el Consulado respectivo. De existir constancia de que la gestación ha sido por cuenta ajena, algunos autores entienden que respecto de la madre debería denegarse la inscripción de la maternidad a nombre de la mujer encargante (por el artículo 187.1 del Código Civil); y respecto del varón, si fue concebido con espermios de él, será filiación no matrimonial, si es con espermio ajeno, podría aplicarse el

51 CORRAL, HeRnÁN, "Maternidad subrogada: sobre la pretensión de formalizar la filiación perseguida mediante la adopción o la recepción de su práctica en el extranjero", en Técnicas de reproducción humana asistida. Desafíos del siglo XXI: una mirada transdisciplinaria, Chile, Universidad de Chile, 2013, pp. 169-182; GÓMEZ DE LA TORRE, MARICRUZ, El sistema filiativo chileno, Santiago, Editorial Jurídica de Chile, 2007, pp. 127-128 y 218; GÓMEZ DE LA TORRE, MARICRUZ, La fecundación in vitro y la filiación, Santiago, Editorial Jurídica de Chile, 1993, p. 197 y SS.

52 JARUFE, DANIELA, "La problemática de la determinación de la filiación derivada de la práctica de la maternidad por subrogación: supuestos que amenazan la estabilidad del sistema filiativo", en Estudios de Derecho civil X, Santiago, 2015, pp. 293-295; RODRíGUEZ, CAMILIO y MARTíneZ, CAROL, "El contrato de maternidad subrogada: la experiencia estadounidense", Revista de Derecho, Valdivia, Universidad Austral, 2012, pp. 63 y ss. 
artículo 182 y tenerse por padre el varón que se sometió a la reproducción asistida. $^{53}$

En el segundo caso, es decir, de ser la maternidad determinada por resolución judicial, debería seguirse el trámite del exequatur (artículo $242 \mathrm{CPC}$ ). De nuevo, parte de la doctrina considera que esta práctica es contraria al orden público chileno (artículo 245, número 1, CPC) y deberá denegarse el exequatur. Si se tratara de una sentencia que regulariza los efectos de dicha maternidad mediante la aplicación de la adopción, tampoco debería tener efectos en Chile por contravenir la Convención de la Haya sobre adopción internacional. ${ }^{54}$

No obstante, si nos hacemos cargo de la experiencia europea, tanto Francia como España inicialmente negaron la inscripción de filiaciones de menores nacidos por maternidad subrogada en el extranjero, por cuestiones de orden público. En el caso francés, el Tribunal Europeo de Derechos Humanos, el 26 de junio 2014, consideró que dicha negativa vulneraba el artículo 8 del Convenio Europeo de Derechos Humanos (respeto a la vida privada y familiar) al no reconocer la filiación entre los menores y los "padres" que han acudido a este método reproductivo. ${ }^{55}$ Por lo tanto, a pesar de la negativa chilena, todo parece indicar que, internacionalmente, en estos casos, el interés de reconocer una filiación al menor en favor de las personas que voluntariamente se someten a la técnica, es el principal interés digno de protección.

Para concluir la breve referencia a los problemas de determinación de la filiación que la reproducción asistida plantea en Chile, hay que hacer referencia a las fecundaciones post mortem. De nuevo, en el ordenamiento chileno no

\footnotetext{
${ }^{53}$ Corral también descarta esta última posibilidad, pues considera que el artículo 182 del Código Civil no está pensando en la admisibilidad de la gestación por cuenta ajena y, por lo tanto, en virtud del artículo 187.1 debería rechazarse la inscripción en favor del varón requiriente, ya que consta fehacientemente que no es el padre biológico del menor. Véase CORRAL, HERNÁN, "Maternidad subrogada: sobre la pretensión de formalizar la filiación perseguida mediante la adopción o la recepción de su práctica en el extranjero", en Técnicas de reproducción humana asistida. Desafíos del siglo XXI: una mirada transdisciplinaria, Chile, Universidad de Chile, 2013, pp. 186-187.

54 CORRAL, HERnÁN, "Maternidad subrogada: sobre la pretensión de formalizar la filiación perseguida mediante la adopción o la recepción de su práctica en el extranjero", en Técnicas de reproducción humana asistida. Desafíos del siglo XXI: una mirada transdisciplinaria, Chile, Universidad de Chile, 2013, pp. 187-188.

${ }^{55}$ Casos Mennesson (asunto 65192/11) y Labasseec. Francia (asunto 65941/11), base de datos del TEDH.
} 
contamos con una regla que precise la admisibilidad o no de este tipo de prácticas. En primer lugar, debemos aclarar que con el término de fecundación post mortem se incluye tanto la reproducción asistida con gametos del varón tras su muerte, como la trasferencia post mortem de embriones preexistentes (producida de una fecundación previa al fallecimiento y una transferencia posterior). En líneas generales, la doctrina se debate a favor y en contra del reconocimiento de esta práctica, en virtud de juicios de ponderación entre el derecho a procrear y el derecho de los menores a nacer en una familia y su deber de asistencia. Tampoco hay unanimidad en las legislaciones que han decidido regular este tipo de prácticas. Países como Italia, Alemania y Francia niegan esta posibilidad. ${ }^{56}$ En Portugal se prohíbe la inseminación post mortem, pero se admite la transferencia post mortem de embriones. ${ }^{57}$ Los argumentos básicamente son el interés del menor a nacer con dos progenitores que le presten asistencia durante su minoría de edad, y que la ponderación entre el perjuicio causado al derecho a procrear de la viuda y el derecho del menor a contar con progenitores desde su nacimiento, debe prevalecer este último.

Sin embargo, en algunos estados de Estados Unidos, en España e Inglaterra, se admite esta posibilidad, pues prima el derecho a la libertad, al libre desarrollo de la personalidad y a la intimidad personal y familiar. Eso sí, se exige el cumplimiento de una serie de requisitos. ${ }^{58}$ Si bien dichos requisitos no son unánimes, se reconoce la filiación del fallecido siempre que hubiera constancia de

\footnotetext{
${ }^{56}$ §4 de la Embryonenschutzgesetsetz de 13 de diciembre de 1990, apartado 3 del artículo 311-20 del Code civil francés y artículo 5 de la Ley de 19 de febrero de $2004 n^{\circ} 40$ sobre Norme in materia di procreazione medicalmente assistita.

${ }_{57}$ Artículo 22 de la Ley 32/2006, de 26 de julio de Prociacao medicamente assitida.

${ }^{58}$ Ley de reproducción asistida española de 2006 y Human Fertilisation and Embryology Act de 2008. En el caso español, en la práctica este consentimiento constituye un anexo al consentimiento general a la reproducción asistida, dado que no es lo mismo el consentimiento para ser padre en vida, que para serlo una vez fallecido. Además, la regulación española establece una presunción de consentimiento en los casos en los que el cónyuge ya hubiera estado sometido a un proceso de reproducción asistida, ya iniciado para la transferencia de preembriones antes de su fallecimiento y hubiera comenzado la administración a la mujer de la medicación necesaria para la técnica. El efecto es la determinación de la filiación matrimonial o no matrimonial, según los casos, y tendrá reconocidos derechos sucesorios. Respecto a la existencia de un plazo, en la legislación española es de doce meses desde el fallecimiento, pues se toman en cuenta las consecuencias jurídicas frente a terceros en materia sucesoria. El plazo permite que la incertidumbre no se prolongua en el tiempo. Véase PÉREZ MONGE, MARINA, La filiación derivada de técnicas de reproducción asistida, Madrid, Centro de Estudios Registrales, 2002, pp. 278 y ss.
} 
un consentimiento expreso y previo a la posibilidad de fecundación post mortem y también que dicha fecundación se lleve a cabo en un plazo relativamente reducido tras el fallecimiento. Además de problemas filiativos, cabe mencionar que la admisibilidad de esta técnica plantea problemas relativos al reconocimiento de derechos sucesorios. De nuevo, existen discrepancias doctrinales entre quienes consideran que no debería considerarse al hijo concebido con dicha práctica heredero. ${ }^{59}$ La mayoría de la doctrina de los países donde esta técnica se admite está a favor de su consideración como heredero. ${ }^{60}$

\section{CONCLUSIÓN}

Chile, al igual que la mayoría de los países en Latinoamérica, no ha logrado establecer leyes que regulen las técnicas de reproducción asistida. Para muchos, esto es un beneficio, pues asumen que las leyes que lo regularían serían más restrictivas de las libertades individuales y harían difícil ofrecer la diversidad de procedimientos que hoy se realizan con poco o ningún control. En mi opinión, esta incertidumbre legislativa impide proteger adecuadamente a los pacientes y supervisar los procedimientos. Igualmente, implica que conceptos bioéticos queden a la voluntad de las personas 0 instituciones que realizan los procedimientos. Sin embargo, concuerdo con Zegers-Hochschild: para que el ordenamiento chileno pueda evolucionar en esta materia, considero necesario que "la influencia de morales particulares se reduzca para que pueda tener lugar una discusión abierta y pragmática sobre si las personas debidamente informadas tienen derecho a decidir qué es lo mejor para ellas y cómo ejercer ese derecho al momento de constituir sus familias". 61

\section{Bibliografía}

\footnotetext{
${ }^{59}$ CorRal, HeRnán, "La procreación artificial post mortem ante el derecho", Revista General de Legislación y Jurisprudencia, Madrid, julio 1988, p. 42.

60 Verdera, Beatriz, "Anotaciones a la Ley de Reproducción asistida", Actualidad Civil, No. 10, Madrid, 2007, p. 10.

61 Zegers-HOCHSCHILD, FeRnANDO, "Algunas consideraciones éticas en la práctica de la reproducción asistida en Lationoamética". [Consulta: 27 de septiembre, 2016]. Disponible en: http://prepre.udp.cl/wp-content/uploads/2014/10/consideraciones_eticas_zegers.pdf
} 
Barber, Roncesvalles, "Reproducción asistida y determinación de la filiación", REDUR, No. 8, Madrid, 2010.

BASCUÑÁN RODRíGUEZ, ANTONIO, "La fecundación in vitro ante el derecho penal chileno", en Técnicas de reproducción humana asistida. Desafíos del siglo XXI: una mirada transdisciplinaria, Santiago, Universidad de Chile, 2013.

Beca, Juan Pablo, lecaros, Alberto, González, Patricio, Sanhueza, Pablo y MANDAKOVIC, BORISLALAVA, "Aspectos médicos, éticos y legales de la criopreservación de embriones humanos", Revista Médica de Chile, Santiago, 2014.

Casas BecerRA, LidiA, "Los desafíos para Chile de la decisión Artavia Murillo contra Costa Rica de la Corte IDH (caso fertilización in vitro): Algunos comentarios", en Anuario de derecho público, Santiago, Universidad Diego Portales, 2013.

CoRRAL, HeRnán, "La procreación artificial post mortem ante el derecho", Revista General de Legislación y Jurisprudencia, Madrid, julio 1988.

Corral, Hernán, Familia y derecho: estudios sobre la realidad jurídica de la familia, Chile, Universidad de los Andes, 1994.

Corral, Hernán, "Maternidad subrogada: sobre la pretensión de formalizar la filiación perseguida mediante la adopción o la recepción de su práctica en el extranjero", en Técnicas de reproducción humana asistida. Desafíos del siglo XXI: una mirada transdisciplinaria, Chile, Universidad de Chile, 2013.

FARNÓS, ESTHER, "La filiación derivada de la reproducción asistida: voluntad y biología", Anuario de derecho civil, vol. 68, fascículo 1, Madrid, 2015.

Gómez dE LA TORRE, MARICRUZ, La fecundación in vitro y la filiación, Santiago, Editorial Jurídica de Chile, 1993.

Gómez de la Torre, Maricruz, El sistema filiativo chileno, Santiago, Editorial Jurídica de Chile, 2007.

Herrera, Florencia, Teitelboim, Berta, Russo, Moisés, Salas, Sofía y ZegersHOCHSCHILD, FERNANDO, "Encuesta de opinión pública sobre reproducción humana y usos de tecnología de reproductiva asistida en habitantes de Santiago, Chile", Revista Médica de Chile, No. 141, Santiago, 2013. 
JARUFE, DANIELA, "Las filiaciones no biológicas derivadas de la aplicación de las TRHA", en Técnicas de reproducción humana asistida. Desafíos del siglo XXI: una mirada transdisciplinaria, Santiago, Universidad de Chile, 2013.

JARUFE, DANIELA, "La problemática de la determinación de la filiación derivada de la práctica de la maternidad por subrogación: supuestos que amenazan la estabilidad del sistema filiativo", en Estudios de Derecho civil $X$, Santiago, 2015.

Marshall, Pablo, Zuñiga, Yanira, Accatino, Daniela y Bordalí, Andrés, "Sentencia sobre inconstitucionalidad del decreto supremo $\mathrm{n}^{\circ} 48$ del Ministerio de Salud en la parte que autoriza la distribución de la 'píldora del día de después' en el Sistema público de Salud (Tribunal Constitucional)", Revista de Derecho, Universidad de Valdivia, julio 2008.

Michel, GRIMALDI, "Observaciones sobre la verdad, la filiación y la reproducción médica asistida", Familia y discapacidad, Madrid, 2010.

Nogueira, Humberto, "Consideraciones jurídicas sobre la jurisprudencia del Tribunal constitucional sobre tratados internacionales y derechos esenciales contenidos en tratados internacionales, después de la reforma constitucional de 2005", Estudios constitucionales, vol. 11, No. 2, Santiago, 2011.

Pérez Monge, Marina, La filiación derivada de técnicas de reproducción asistida, Madrid, Centro de Estudios Registrales, 2002.

Rodríguez, Camilio y Martínez, Carol, "El contrato de maternidad subrogada: la experiencia estadounidense", Revista de Derecho, Valdivia, Universidad Austral, 2012.

ROSENDE, Hugo, “¿Es inconstitucionalidad la norma del inciso $2^{\circ}$ del artículo 182 del Código civil chileno que impide impugnar la filiación determinada del hijo concebido mediante técnicas de reproducción humana asistida o reclamar otra distinta?, Revista Actualidad Jurídica, No. 23, enero 2011.

Ruiz Miguel, Alfonso y ZúÑIga Fajuri, Alejandra, "Derecho a la vida y constitución: consecuencias de la sentencia de la Corte Interamericana de 
Derechos humanos 'Artavia Murillo vs. Costa Rica', Estudios Constitucionales, año 12, No. 1, Talca, 2014.

Sentencia del Tribunal Constitucional de 18 de abril de 2008, Rol 741-07 CDS, considerandos 49 y 53.

TURNER, SUSAN, "Los derechos sexuales y reproductivos y su incidencia en la esterilización y procreación asistida", Revista de Derecho, Valdivia, diciembre 2001.

Turner, Susan, Molina, Marcia y Momberg, Rodrigo, "Técnicas de reproducción humana asistida. Una perspectiva desde los intereses del hijo", Revista de Derecho, Talca, 2000.

UndURRAGA, VerónICA, "Anticoncepción de emergencia: autonomía de las adolescentes y derechos de sus padres", Anuario de Derechos Humanos, Santiago, 2007.

Verdera, Beatriz, "Anotaciones a la Ley de Reproducción asistida", Actualidad Civil, No. 10, Madrid, 2007.

Zegers-Hochschild, Fernando, "Algunas reflexiones éticas en el uso de la tecnología reproductiva moderna para el tratamiento de la infertilidad", Revista Médica Clínica las Condes, vol. 21, No. 3, Santiago, 2010.

ZeGERS-HOCHSCHILD, FERNANDO, "Algunas consideraciones éticas en la práctica de la reproducción asistida en Lationoamética". [Consulta: 27 de septiembre, 2016]. Disponible en: http://prepre.udp.cl/wpcontent/uploads/2014/10/consideraciones_eticas_zegers.pdf

Zegers-Hochschild, Fernando, Dickens, Bernard y Dughman, Sandra, "El derecho humano a la fecundación in vitro", Revista Chilena de Obstetricia Ginecológica, vol. 79, No. 3, Santiago, 2014.

Zegers-Hochschild, Fernando, Nygren, Karl G. Y Ishihara, Osamu, "The impact of legislation and socioeconomic factors in the access to a global practice of assisted reproduction", en Texbook of Assisted Reproductive Techniques: Clinical Perspective, Florida, 2008.

Zegers-Hochschild, Fernando, Scwarze, Juan Enrique, Crosby, Javier y Borges, María Do CARmo, "Twenty years os Assisted Reproductive 
Technology ART) in Latin America", en JBRA Assit. Reprod., vol.15, No. 2, March-April, 2011.

ZUÑIGA, FRANCISCO, "Sentencia de la Corte Interamericana de Derechos Humanos en el caso Artavia Murillo y otros (fecundación in vitro) vs. Costa Rica", Anuario de Derecho público UDP, Santiago, 2013. 